\title{
Social power: To use or not to use?
}

\author{
KATHY SHELEY \\ University of Texas, San Antonio, Texas 78284 \\ and \\ MARVIN E. SHAW \\ University of Florida, Gainesville, Florida 32611
}

\begin{abstract}
An experiment was conducted to test the hypothesis that use of reward power possessed by a leader increases group productivity, whereas use of coercive power decreases productivity. Leaders of two-person groups selected sets of anagrams to be attempted by the follower. Half of the leaders had control over rewards (additional points for good performance) and half had control over punishments (few points for poor performance). Half of the leaders in each condition used their power and half did not. Just before the final trial, the leader made a special appeal to the follower to exert more effort to solve as many of the anagrams as possible. The results supported the hypothesis with regard to the use-nonuse of coercive power but not with regard to the use or nonuse of reward power. These findings were interpreted in terms of affective relations between leaders and followers.
\end{abstract}

Social power is one of the most significant determinants of social interaction, but it is also one of the most inadequately articulated concepts in the social sciences. Social power is variously defined as an attribute of a relationship (Emerson, 1964), as the net force that one person can exert on another (French, 1956; Lewin, 1951), and as the ability to control the outcomes of another person (Thibaut \& Kelley, 1959). Furthermore, relatively few experimental studies have been conducted and still fewer have distinguished between the possession of power and the use of power. The present study is concerned with the use or nonuse of power by a powerful leader, where power is defined as the control of reinforcers (Shaw, 1976). This definition is consistent with most of those listed above, as well as those proposed by Bass (1960) and Mulder (1960).

Several aspects of the situation must be considered in analyzing the effects of social power on group processes. A powerful group member may (1) act as if he or she had no power, (2) threaten or promise to use power, or (3) use power, with or without prior threat or promise. In most investigations reported in the literature, the amount of power possessed by a group member is manipulated, but the powerful group member is free to use or not use the power as he or she wishes. Furthermore, the interpretation of experimental results is often complicated by the simultaneous variation of amount of reward and coercive power possessed by group members, by participants being unaware of the actual amount of power they possessed, and/or by combining possession of power with the use of threats and/or promises. For

Our sincerest thanks are due to Eugene Matter and Vance Geiger, the experimenter and confederate, respectively. instance, Butler and Miller (1965) conducted two experiments to evaluate the effects of reward and coercive power on the communication patterns in three-person groups. Power was defined as the probability of successfully completing an attempt to reward or punish another group member. Each person in the group could send a message to each of the other two group members on each of several trials, each message indicating that the other person should either receive an added 1 cent or have 1 cent subtracted from final earnings. Although each person believed that he or she could reward or punish on every trial, the amount of actual power possessed by each person was manipulated by the delivery or nondelivery of messages by the experimenter. Each member possessed some power, but the ratio of reward to coercive power varied both within and between groups. The results showed that more rewards and fewer punishments were addressed to persons possessing high reward power, that reward power was more effective than punishment power in determining number of punishments addressed to a person, and that mild punishment was ineffective in controlling others. With regard to the latter finding, it should be noted that in these experiments use of coercive power was also a failure to use reward power.

In a somewhat similar study, Miller, Butler, and McMartin (1969) found that increments in ability to reward others had greater effects on their behavior (number of positive messages sent) than comparable amounts of coercive power. They suggested that nonuse of coercive power might be more effective than use of such power. As in the Butler and Miller (1965) study, the effects of reward and coercive power could not be clearly separated.

Experiments that couple the possession and use of 
power with threats and/or promises yield results that are not altogether consistent with the Miller et al. (1969) suggestion. In one study (Schlenker \& Tedeschi, 1973), group members were provided either reward power, coercive power, or reward and coercive power in a modified prisoner's dilemma situation. Schlenker and Tedeschi found that individuals who had coercive power or both reward and coercive power made more influence attempts and established higher credibility for their influence attempts than did individuals who had only reward power.

Given the above considerations, this research was begun with the a priori expectation that the use of reward power by a leader would increase his or her influence on the group (and hence increase group productivity), whereas use of coercive power by a leader would decrease his or her influence on the group (and hence decrease productivity). Therefore, given that a leader attempts to increase productivity, an interaction between type of power and use of power was predicted such that, relative to nonuse of power, use of reward power will increase productivity and use of coercive power will decrease productivity.

\section{METHOD}

The predictions were tested in a 2 by 2 factorial experiment investigating type of power (reward vs. coercive) and employment of power (use or nonuse). Dependent variables included actual problem-solving performance on a critical final trial, self-ratings of performance both throughout the experiment and on the final trial, self-ratings of effort expended on the critical trial, and ratings of various attributes of the powerful person.

\begin{abstract}
Subjects
Subjects were 48 male undergraduates enrolled in introductory psychology courses who participated to partially fulfill course requirements. Twelve subjects were randomly assigned to each of the four experimental conditions. Another undergraduate served as a confederate and participated in all experimental sessions.
\end{abstract}

\section{Procedure}

One subject and the confederate participated in each session. Both subject and confederate were greeted in a waiting room by the experimenter, who escorted them to the experimental room. Subjects were told that we were interested in group productivity in situations where group members have different jobs, that in this instance Person A would make decisions and Person B would be required to carry them out, that their task was to complete several anagram sets, and that Person B would receive two points for each anagram set completed. In the reward condition, subjects were told that Person A could increase earnings by one point per set, whereas in the coercive condition they were told that Person A could decrease earnings by one point per set. Finally, subjects were told that the decision to use or not to use this power was A's choice and that A's performance would be evaluated in terms of the number of anagram sets completed by $B$.

Subject and confederate then participated in a contrived drawing through which the subject was assigned the role of Person B. Following completion of a sample set of anagrams, Person A selected the set of anagrams to be attempted on the first trial and the experimenter repeated the instructions about available power and A's option to use it or not. On each of eight trials, Person B attempted to solve six anagrams. Person A stated in each instance that B should be able to complete four of the six anagrams. At the end of each trial, the experimenter scored B's work and A allocated a predetermined number of points. In order to make the use or nonuse of reward or coercive power appear reasonable, or at least not purely capricious, the anagram tasks selected for the coercive condition were slightly more difficult than those selected for the reward condition.

Following each trial, A made appropriate remarks (standardized) designed to justify his use or nonuse of power. For example, in the use of reward condition at the end of the first trial, A said, "You (only) got__ right. (But) I guess that's worth three points." After trial two, he said, "Yeah, I'll give you three." After each of Trials 3-7, A noted that three points were earned. Words in parentheses were used whenever B's performance was lower than anticipated.

Before beginning the eighth (and final) trial, in all conditions, A said, "All right, this is the last trial, and it's my last chance to get a high score in the experiment. So try to do the best job you can on this one." After the final trial, both A and B completed a questionnaire containing items designed to determine members' reactions to the leader and their motivations to achieve. Subjects were then fully debriefed.

\section{RESULTS}

\section{Manipulation Checks}

Responses to questions designed to determine the participant's perception of the experimental situations indicated that manipulations of variables were successful. Subjects correctly perceived (1) that they had less power (mean $=7.26$, where a high score reflects low power) than the other person (mean $=4.28)[\mathrm{F}(1,42)=$ 43.87, $\mathrm{p}<.001] ;^{1}(2)$ that the other person had either reward power (mean $=2.35$, where low scores reflect reward power) or coercive power $($ mean $=4.26)$ $[F(1,42)=14.60, p=.0004]$; and (3) that the powerful person either used his power (mean $=6.83$, where high scores indicate use of power) or did not use his power $($ mean $=5.18)[F(1,42)=5.23, p=.03]$. No interaction was significant.

\section{Group Performance}

The measure of group performance was the number of anagrams solved correctly on each trial. Our major interest was in performance on the final trial (after the leader had requested a special effort on the part of the group members) relative to earlier performance. The score employed was the difference in performance (number of anagrams completed) between the seventh and the eighth trials (score on eighth minus score on seventh trial). ${ }^{2}$ Analysis of variance revealed significant differences attributable to type of power (mean for reward power $=.17$, mean for coercive power $=1.42$ ) $[F(1,44)=11.87, p<.0001]$, to use of power (mean for use of power $=.42$, mean for nonuse $=1.17)[(1,44)$ $=4.32, \mathrm{p}<.05]$, and to the interaction of type and use of power $[F(1,44)=11.82, p<.0001]$. The interaction means are presented in Figure 1. Duncan's range test 




Figure 1. Change in number of anagrams completed as a function of type and use of power.

indicated that the mean for unused coercive power differed significantly from all other means, which did not differ from each other. In other words, the leader had significantly more influence on the group's performance when he did not use coercive power than when he did use it, but his influence was not significantly affected by use or nonuse of reward power. These findings agree with expectations about the relative effectiveness of use and nonuse of coercive power but not with expectations about the use or nonuse of reward power.

\section{Questionnaire Results}

Analysis of variance of ratings of the fairness of the leader revealed a significant Type of Power by Use of Power interaction $[F(1,42)=5.31, p=.0262]$. These interaction means are depicted in Figure 2. Duncan's range test indicated that the reward-used mean differed significantly from all others $(p<.05)$. The leader was rated as being more fair when he used reward power than when he did not or when he possessed coercive power, whether used or not.

Responses to the question, "How hard did you work on the LAST trial of the experiment?" revealed the now usual Type of Power by Use of Power interaction $[F(1,42)=7.38, p=.0095]$. Figure 3 presents the interaction means. Duncan's test indicated that only the reward-used and coercive-used means differed significantly $(p<.05)$. Participants indicated they tried harder on the last trial when the powerful person did not use coercive power than when he did not use reward power.

Group members' ratings of their performance generally indicated valid perceptions. Analysis of ratings of overall performance resulted in a Type of Power by Use of Power interaction $[F(1,42)=4.52, p=.039]$. Duncan's test showed that all means differed significantly $(p<.05)$ except the reward-used and rewardunused means. Group members believed (correctly) that they performed better when coercive power was not used than when it was used.
In response to the question, "How well do you think you performed on the LAST trial of the experiment?"; group members accurately indicated that they performed significantly better when the leader possessed reward power $($ mean $=2.70$, where a low score indicates perceived better performance) than when the leader had coercive power $($ mean $=6.00) \quad[\mathrm{F}(1,42)=31.59$, $\mathrm{p}=.0001]$. Again, there was a significant Type of Power by Use of Power interaction $[F(1,42)=9.07, p=.0044]$. Duncan's test showed that participants rated their performance lower when the leader used coercive power than when he did not $(p<.05)$, whereas ratings of performance were not significantly different for reward used and reward not used.

Questions concerned with participants' evaluation of the powerful person, desire to please him on the last trial, and liking to work with him again yielded insignificant results.

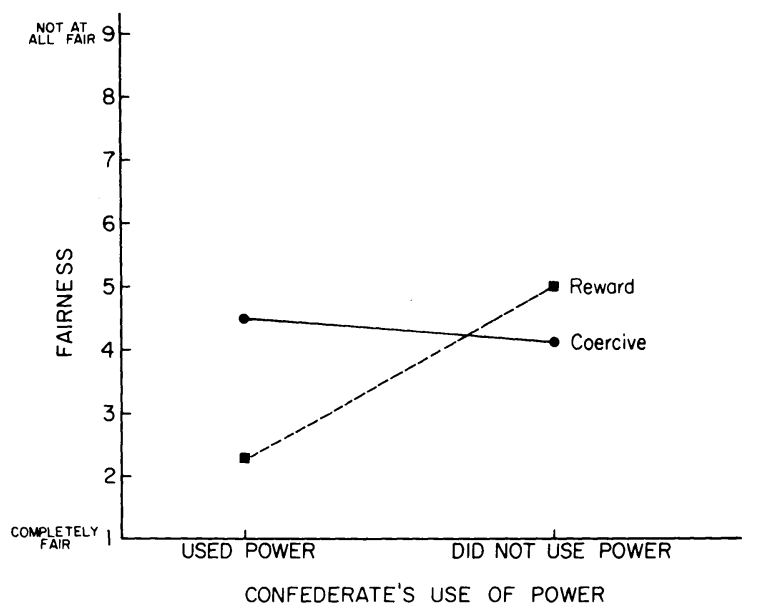

Figure 2. Ratings of fairness of the powerful person as a function of type and use of power.

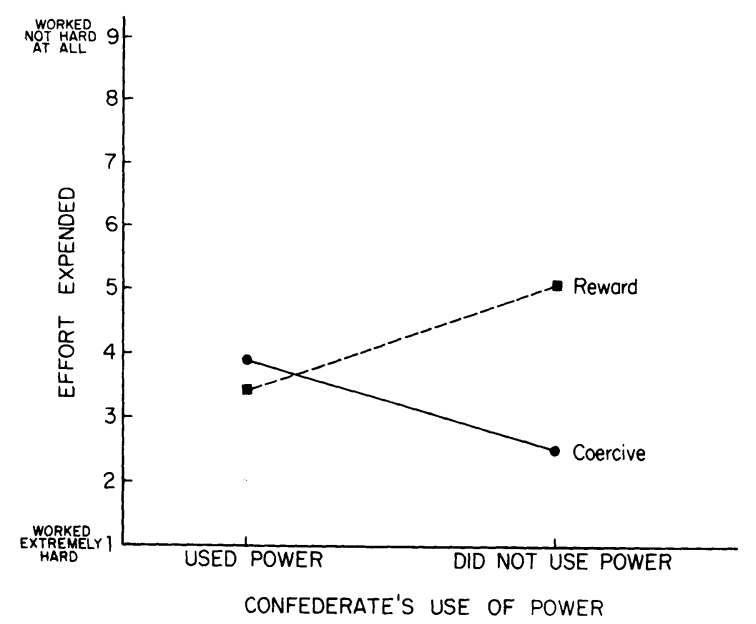

Figure 3. Ratings of effort expended on last trial by participants as a function of type and use of power. 


\section{DISCUSSION}

The results from this experiment are not entirely in accord with previous findings. For example, the data reported here are inconsistent with the findings of Butler and Miller (1965) and Miller et al. (1969), which indicated that reward power was more effective than coercive power. There are several differences, however, between those experiments and the present one. Whereas previous researchers assigned power to all group members, reward or coercive power or both, and permitted members to believe they were free to exercise that power or not, the present research separated the possession of power from the use of power. They also measured the effects of power upon the exchange of rewards and punishments (via messages), whereas we measured productivity and reactions to the powerful person.

The findings from this experiment thus contributed new data concerning the relative effectiveness of using reward or coercive power, in contrast to merely possessing power. Productivity was not improved by using either reward or coercive power relative to mere possession of power, and using coercive power actually decreased productivity when the powerful person requested that the subject make a special effort (on the eighth trial). It is possible that participants in the reward condition were performing near maximum when the powerful person used his power. If so, a ceiling effect may have prevented improvement in performance when the leader requested a special effort. However, there was ample room for group members to reduce productivity when the leader had refused to reward them, but this did not occur. In any event, the results of this study suggest that a person who possesses only coercive power will be more effective if he does not use his power, or perhaps uses it sparingly.

The manner in which use of coercive power reduces productivity is not entirely clear from data obtained in this study. It appears that the use of coercive power elicits negative feelings toward the powerful person, causing that person to exert less effort and to perform less well when coercive power is used than when it is not. This interpretation has some support from questionnaire results. Participants rated both their overall and terminal performance lower and indicated that they did not try as hard on the final trial, after the powerful had requested a special effort, when the powerful person used coercive power than when he did not.

\section{REFERENCES}

BAss, B. M. Leadership, psychology, and organizational behavior. New York: Harper \& Row, 1960.

Butler, D. C., \& Miller, N. Power to reward and punish in social interaction. Journal of Experimental Social Psychology, 1965, 1, 311-322.

EMERSON, R. M. Power-dependence relations: Two experiments. Sociometry, 1964, 27, 282-298.

French, J. R. P., JR. A formal theory of social power. Psychological Review, 1956, 63, 181-194.

LEWIN, K. Field theory in social science. New York: Harper, 1951.

Miller, N., Butler, D. C., \& McMartin, J. A. The ineffectiveness of punishment power in group interaction. Sociometry, 1969, 32, 24-42.

MULDER, M. The power variable in communication experiments. Human Relations, 1960, 13, 241-257.

SChLENKER, B. R., \& TEDESCHI, J. T. Interpersonal attraction and the exercise of coercive and proper power. Human Relations, 1973, 25, 427-439.

Shaw, M. E. Group dynamics: The psychology of small group behavior (2nd ed.). New York: McGraw-Hill, 1976.

ThiBAUT, J. W., \& KelleY, H. H. The social psychology of groups. New York: Wiley, 1959.

\section{NOTES}

1. Two participants failed to complete the questionnaire; therefore, all analyses of questionnaire data are based upon the responses of 46 subjects.

2. It might be worth noting that the results are the same when performance on the final trial is compared with the average performance on the first seven trials.

(Received for publication January 31, 1979.) 